\title{
Cities as Centers of Innovation
}

\author{
Rubén Hernández-Murillo
}

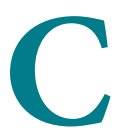

ities have traditionally been seen as important centers of economic activity, particularly for manufacturing. Recently, economists have found that densely populated areas are increasingly providing the best environment to facilitate the diffusion of new ideas, in addition to serving as the location for the production of goods. ${ }^{1}$ The reason is that the agglomeration of people and firms in urban areas promotes a faster exchange of information and ideas and this generates new technologies.

One way to measure technological innovation is to look at statistics on patents. Recently available data also provide a means to track patent activity by specific category and geographical area, making it possible to study the innovation performance of regions. ${ }^{2}$

During the last two decades, almost 90 percent of all utility patents in the United States were granted to residents of metropolitan areas. ${ }^{3}$ During the 1990s, the metro area with the highest patent count per 10,000 people was San Jose, California-the heart of Silicon Valley-with a rate of 162. Other cities with high innovation rates were Rochester, New York (with a rate of 112), Boulder, Colorado (with a rate of 100), Trenton, New Jersey, and Danbury, Connecticut (both with a rate of 89), and Boise, Idaho (with a rate of 84). Although the degree of innovation among U.S. cities varies substantially, essentially all metro areas generated patents at a faster rate in the 1990s than in the previous decade.

Cities have shifted away from the production of traditional manufacturing goods to become centers of innovation, a trend that can be seen by analyzing patent counts across technological fields. The total number of patents granted in metropolitan areas accelerated from a 3.4 percent annual rate of growth in the 1980 s to a 6.8 percent annual rate in the $1990 \mathrm{~s}$. Specifically, as shown in the figure, the increase in patenting in the computers and communications sector and in the pharmaceutical and medical sector during the 1990s was remarkable. Innovation in the computers and communications sector rose at an annual rate of 15.8 percent during the 1990s-about twice as fast as in the 1980s. In the pharmaceutical and medical sector, patent counts increased at an annual rate of 12.2 percentabout 4.3 percentage points faster than in the 1980s. Innovation in traditional goods-producing sectors (such as chemical, mechanical, and electrical and electronics) also increased more in the 1990s than in the 1980s, but the uptick in growth rates was not as large. 4 This pattern in patent activity reflects the high-tech revolution associated with the emergence of information technologies and the life sciences, particularly in the latter part of the 1990s.

\footnotetext{
${ }^{1}$ Carlino, Gerald; Chatterjee, Satyajit and Hunt, Robert. "Knowledge Spillovers and the New Economy of Cities." Working Paper No. 01-14, Federal Reserve Bank of Philadelphia, September 2001.

${ }^{2}$ Hall, Bronwyn H.; Jaffe, Adam B. and Trajtenberg, Manuel. "The NBER Patent Citations Data File: Lessons, Insights and Methodological Tools.” NBER Working Paper No. 8498, National Bureau of Economic Research, 2001.

${ }^{3}$ There are several patent categories, but utility patents constitute the large majority.

${ }^{4}$ The data used are from the NBER patent database. The calculations and matching of metropolitan areas were performed by the author.
}

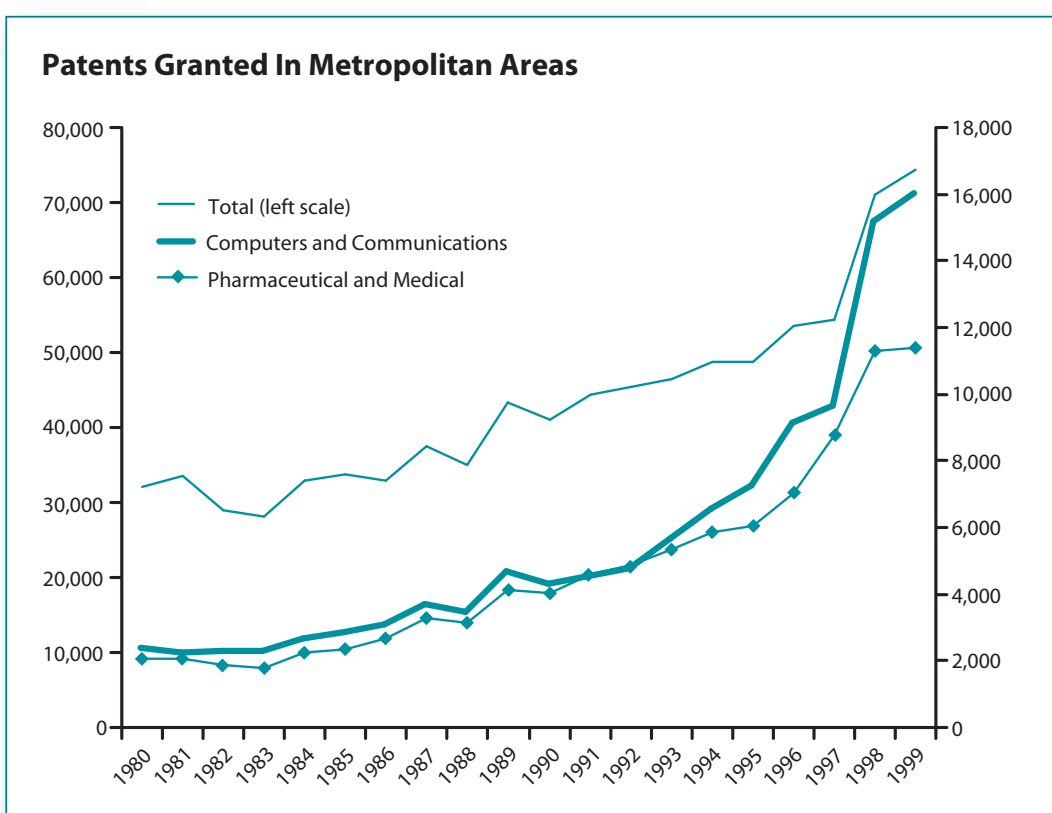

Views expressed do not necessarily reflect official positions of the Federal Reserve System. 